\title{
Optimization of Fiscal and Tax Policy for Manufacturing Industry Transformation and Upgrading Under the Supply-side Structural Reform
}

\author{
Based on Tianjin's Macro Data Analysis* \\ Yue Wang \\ College of Economics\& Management \\ Tianjin Agricultural University \\ Tianjin, China 300384
}

\author{
Caixia $\mathrm{Li}^{* *}$ \\ College of Economics\& Management \\ Tianjin Agricultural University \\ Tianjin, China 300384 \\ **Corresponding Author
}

\author{
Xian Han \\ Accounting Institute \\ Tianjin University of Finance and Economics \\ Tianjin, China 300222
}

\begin{abstract}
Manufacturing industry is China's advantageous industry and an important pillar and foundation of the national economy, plays an important role in the development of the national economy, and is also the basis for establishing the country, the device for rejuvenating the country and the foundation for strengthening the nation. Against the background of supply-side structural reforms, it has great practical significance on research of the support to the manufacturing industry transformation and upgrading by the fiscal and tax policy. Therefore, based on the analysis of the macro data of Tianjin, this paper studies the fiscal and tax policy constraints faced by the transformation and upgrading of Tianjin's manufacturing industry, and proposes targeted policy recommendations, in order to create the external environment for manufacturing industry transform and upgrade, and effectively serve the supply-side structural reform.
\end{abstract}

Keywords-supply-side structural reform; manufacturing industry; transformation and upgrading; fiscal and tax policy

\section{INTRODUCTION}

Since the "Supply-side Structural Reform" was put forward, its basic purpose is to optimize the supply structure, quality and efficiency, which points out the direction for China's economic development at the present stage. We will continue to strengthen the deployment of enterprise technology upgrading and transforming, in order to promote the industry towards the medium and high-end and other

*Fund: Tianjin's Philosophy and Social Science Planning Project (TJYY16-0230; Tianjin's Science and Technology Development Strategy Research Planning Project; Tianjin's agricultural college MPAcc professional teacher scientific research project. Classification number: F275.5; Document identifier: A related policies have been implemented one after another [1] As an important pillar of China's national economy and an important component of the real economy, manufacturing industry's development is facing some challenges. At present, its industrial layout, industrial clusters, industrial development and other aspects have orderly advanced by fiscal and tax policy to continue to guide the transformation and upgrading of the manufacturing industry. Although the transformation and upgrading of China's manufacturing industry has achieved phased results, it is still need to improve the effectiveness of policies to promote the transformation and upgrading of the manufacturing industry. It is urgent to continuously optimize the policy environment for the transformation and upgrading of the manufacturing industry.

As the origin of China's modern industry, manufacturing industry occupies an important position in Tianjin's industry. At the end of "12th Five-year Plan", the output value of Tianjin's eight dominant pillar industries accounts for $89.5 \%$ of the city's total industrial output value, advanced manufacturing industries accounted for more than $50 \%$ of the total industrial output value, equipment manufacturing has become an industry that has trillions of estate, aviation and aerospace present the industrial pattern of "three aircraft, one arrow, one star and one station". However, there are still some deep-seated problems and contradictions in the development of manufacturing industry in Tianjin. Given the lag in the market itself, the government should promote the transformation and upgrading of manufacturing industry by using the fiscal and tax policy to guide. Therefore, based on the macroeconomic data of Tianjin, this paper analyzes the fiscal and tax policy constraints faced by the transformation and upgrading of manufacturing industry, and puts forward 
fiscal and tax policy suggestions to promote the transformation and upgrading of manufacturing industry in Tianjin.

\section{THE MECHANISM OF FISCAL AND TAX POLICY SUPPORTING THE TRANSFORMATION AND UPGRADING OF MANUFACTURING INDUSTRY}

\section{A. Macro-controlling the Direction of Resource Flow}

As a macro-control tool of the government for economic operation, fiscal and tax policy has an important guiding effect on the flow direction of the resource and provides core support for the construction of manufacturing powerhouse. Through the combination of economic, industrial, regional, technological and other policies, the government has targeted to formulate supporting fiscal and tax policy to promote the flow of resources into the advantageous industries and out of the backward industries of the manufacturing industry, and ultimately achieve the transformation and upgrading of the manufacturing industry. By formulating reasonable and scientific fiscal and tax policy, it is helpful to realize the effective allocation of resources and the optimal combination of economic structure, and to achieve the rationalization of industrial structure, product structure and regional distribution of manufacturing industry. For example, aiming at financial subsidies for smart manufacturing enterprises, it will promote the social effective resources to flow into the emerging manufacturing industries or smart manufacturing; on the contrary, the implementation of tax surcharges on high-energy consuming manufacturing enterprises will promote the elimination of backward production capacity. It can be seen that scientific and reasonable fiscal and tax policy can promote the effective flow of resources within the manufacturing industry and contribute to the transformation and upgrading of the manufacturing industry.

\section{B. Promoting the Endogenous Power of Enterprise Innovation}

When the world's economies regard innovation as the core power to promote and support the development of the manufacturing industry in the future [2], according to the current economic and industrial needs, Tianjin and even the national government should formulate the supporting fiscal and tax policy to promote enterprise innovation, adjust the process of resource allocation in market mechanism, and promote the flow of economic resources to the direction conducive to independent innovation. In addition, formulate fiscal and tax policy for the transformation of scientific research achievements of scientific research institutions and universities, and effectively direct independent innovation achievements to transfer to enterprise, which make economic development really benefits from the practice, application and industrialization of new technological achievements. Increasing fiscal and tax policy to support innovation will effectively leverage the endogenous power of enterprise $\mathrm{R} \& \mathrm{D}$, and reduce the risk of enterprise innovation; at the same time, the supporting from fiscal and tax policy will foster good innovation spirit and business philosophy of enterprises, and promote the connotative development of manufacturing industry.

\section{Appropriately Resolving the Risks of Scientific and Technological Innovation in Enterprises}

Due to the large scale of investment, long recovery cycle and high uncertainty in technological innovation activities of enterprises, the risk of innovation failure is large, so the support of fiscal and tax policy is particularly important. Fiscal and tax policy can appropriately reduce the loss of $\mathrm{R} \& \mathrm{D}$ expenditure on scientific and technological innovation, and enhance the ability of enterprises to resist risks. When an enterprise conducts independent $\mathrm{R} \& \mathrm{D}$, it will face a higher risk of failure, if the government increases the funding for it at this time, the internal funds used by the enterprise for $R \& D$ will be reduced, so that the risk of failure in $R \& D$ of the enterprise will be greatly reduced. It can be seen that the well-directed fiscal and tax policy is conducive to reducing $\mathrm{R} \& \mathrm{D}$ costs, reducing $\mathrm{R} \& \mathrm{D}$ risks, creating a favorable innovation environment and stimulating the vitality of innovation subjects.

\section{Directly or Indirectly Affecting the Cost Benefit of Enterprises}

The main task of supply-side structural reform is "Capacity reduction \& De-stocking \&Deleveraging, Cost reduction, improving underdeveloped areas", among which "one reduction" is cost reduction. Only by effectively lowering costs can promote the development of the real economy and realize the transformation and upgrading of the manufacturing industry. On the one hand, fiscal and tax policy can directly reduce the burden of manufacturing industry by adjusting production factors, meanwhile, it also provides a good development environment for manufacturing industry, which affects the cost benefit of manufacturing enterprises. On the other hand, tax revenue is one of the important costs of the enterprise and an important parameter in the enterprise economic operation, it will have a direct impact on the efficiency of enterprise production and operation; its explicit or implicit costs of tax payment activities will also affect corporate benefits. Similarly, fiscal and tax policy can directly increase corporate benefits.

\section{FISCAL AND TAX POLICY CONSTRAINTS FACED BY THE TRANSFORMATION AND UPGRADING OF MANUFACTURING INDUSTRY}

\section{A. Fiscal and Tax Policy to Promote the Adjustment of the Industrial Structure of Manufacturing Industry Still Needs to Be Optimized}

The manufacturing industry in Tianjin has a long history of development and a solid strength foundation, it accounts for $89 \%$ of the output value of Tianjin's industry, in 2016 Tianjin's advanced manufacturing industry enjoyed a good momentum of development, forming a development situation of "intensive, cluster and gather". The added value of equipment manufacturing accounted for $36.1 \%$ of the industries above designated size, the added value of consumer goods manufacturing accounted for $20.8 \%$, the 
added value of competitive industries accounted for $91.0 \%$, and the added value of emerging industries such as aerospace, new materials and biological medicine accounted for $16.5 \%$ [3]. As the largest industry in Tianjin's manufacturing industry, equipment manufacturing industry has a high investment in $R \& D$ activities and a high risk. Only the government leads, increases the financial support dynamics, can the industry will be better and faster to achieve transformation and upgrading.

However, the fiscal and tax policy to guide the development of manufacturing industry and investment orientation still needs to be improved. The preferential tax policies that promote the industrial structure adjustment of the manufacturing industry are relatively scattered, lacking a complete and systematic guiding mechanism for the development of the manufacturing industry, and mainly in the form of direct tax reduction and exemption, lacking longterm and sustainable incentives. For example, R\&D expenditure plus deduction, the critical equipment investments of environmental protection and the state encourages investment are pre-tax deducted, fixed assets accelerated depreciation preferences and so on. Regular tax incentives are not only applicable to manufacturing industry, but also to other industries, the specific tax support and incentive policies for manufacturing industry in the tax system are relatively few, which is not conducive to supporting the development of manufacturing industry.

\section{B. Fiscal and Tax Policy to Encourage Independent}

Innovation in the Manufacturing Sector Needs to Be Improved

The transformation and upgrading of the manufacturing industry depends on high and new technology that derives from basic R\&D. According to the endogenous growth theory model of technological progress, technological progress is the core of economic growth, and knowledge innovation is the theoretical basis of technological progress, and the R\&D investment in technological innovation can bring knowledge innovation [4]. Therefore, in the aspect of supporting manufacturing transformation, financial funds should focus on investment in basic R\&D. At present, Tianjin has not formed a complete system of fiscal expenditure and use to promote the development of manufacturing industry, there is no incentive policy to support basic research in fiscal policy, and no attention is paid to the innovation input of scientific research achievements. Tianjin's related special fund management interim measures are cleared that the specific support scope of the fund, but the focus of support for the manufacturing industry is not clear, which makes the fiscal and tax policy to promote the upgrading of the manufacturing industry not clear. By comparing the investment in R\&D in Tianjin, Shanghai and Beijing from 2011 to 2015 and its proportion in the GDP of each region (see "Table I"), it can be seen that although the R\&D investment in Tianjin has been growing for five consecutive years, the proportion of annual R\&D investment in GDP is far lower than that in Beijing and Shanghai. In recent years, Tianjin's proportion of $R \& D$ spending in GDP has been maintained at $2.6 \%$ to $3.1 \%$, with a small growth rate; Shanghai proportion of $R \& D$ expenditure in GDP increased from $3.11 \%$ to $3.73 \%$ Beijing's proportion of R\&D expenditure in GDP increased from $5.76 \%$ to $6.01 \%$. In addition, Tianjin's fiscal support for high-tech development has increased, Tianjin's fiscal expenditure on science and technology and its proportion in municipal public fiscal expenditure continued to increase from 2011 to 2015, but the increase was not obvious (see "Table II"). This shows that there is still room for improvement in R\&D investment in Tianjin, which still needs to be promoted by fiscal and tax policy.

TABLE I. 2011-2015 R\&D FundING OF TIANJIN, BEIJING AND SHANGHAI AND ITS PROPORTION IN GDP

\begin{tabular}{|l|l|l|l|l|l|l|}
\hline \multirow{2}{*}{ Year } & \multicolumn{2}{|c|}{ Tianjin } & \multicolumn{2}{c|}{ Shanghai } & \multicolumn{2}{c|}{ Beijing } \\
\cline { 2 - 7 } & $\begin{array}{l}\text { R\&D expenditure } \\
\text { hundred million } \\
\text { yuan) }\end{array}$ & $\begin{array}{l}\text { Proportion of } \\
R \& D \text { expenditure } \\
\text { in GDP(\%) }\end{array}$ & $\begin{array}{l}\text { R\&D expenditure } \\
\text { (hundred million } \\
\text { yuan) }\end{array}$ & $\begin{array}{l}\text { Proportion of } \\
R \& D \text { expenditure } \\
\text { in GDP(\%) }\end{array}$ & $\begin{array}{l}\text { R\&D expenditure } \\
\text { (hundred million } \\
\text { yuan) }\end{array}$ & $\begin{array}{l}\text { Proportion of } \\
R \& D \text { expenditure } \\
\text { in GDP(\%) }\end{array}$ \\
\hline 2011 & 297.76 & 2.63 & 597.71 & 3.11 & 936.64 & 5.76 \\
\hline 2012 & 360.49 & 2.8 & 679.46 & 3.37 & 1063.36 & 5.95 \\
\hline 2013 & 428.09 & 2.96 & 776.78 & 3.56 & 1185.04 & 5.98 \\
\hline 2014 & 464.69 & 2.95 & 861.95 & 3.66 & 1268.79 & 5.95 \\
\hline 2015 & 510.18 & 3.08 & 3.76 & 1384.02 & 6.01 \\
\hline
\end{tabular}

TABLE II. TIANJIN'S FinANCIAL TECHNOLOGY SPENDING IN 2011-2015

\begin{tabular}{|c|c|c|c|c|c|}
\hline Item & 2011 & 2012 & 2013 & 2014 & 2015 \\
\hline Municipal expenditure on financial technology (million dollars) & 32.1 & 38.85 & 44.78 & 50.28 & 53.63 \\
\hline Proportion of municipal expenditure on financial technology in public finance (\%) & 3.95 & 4.17 & 4.3 & 4.63 & 4.58 \\
\hline
\end{tabular}




\section{Fiscal and Tax Policy to Encourage the Development of Green Manufacturing Is Incomplete}

In order to implement the national requirements of gradually establishing a domestic carbon emission trading market, Tianjin as one of the pilot cities for carbon emission trading, "Implementation Plan of Tianjin Municipal Carbon Emission Trading Pilot Project" was promulgated in 2013, and had included enterprises that have emitted over 20,000 tons of CO2 since 2009 in key emission industries and civil construction field in the trading scope [5]. By collecting and organizing data, we can see that most of the 28 industries with CO2 emission of over 20,000 tons in Tianjin are manufacturing enterprises, the petrochemical, steel, nonferrous metal and other traditional industries account for more than $50 \%$ among the manufacturing industries in Tianjin, which directly leads to serious carbon pollution and great pressure to reduce carbon pollution in Tianjin; In addition, the proportion of industrial waste water and waste gas pollutants in the total emissions of Tianjin is greater than that of Beijing, and the industrial waste gas emissions in the Beijing-Tianjin-Hebei region have ranked first. While the tax policy as an important means to achieve the goal of energy conservation \& emission reduction and the government's macro-economic regulation, which should be integrated system specified and improve tax policy to make the transformation and upgrading of high-energy consuming enterprises as the focus of the transformation and upgrading of Tianjin's manufacturing sector, so as to promote energy conservation \& emission reduction, and encourage the development of green manufacturing [6].

\section{Fiscal and Tax Policy to Support Manufacturing Venture Financing Needs to Be Perfect}

Tax policy, as an effective support for venture capital financing, has a limited scope and does not involve the investment of venture capital institutions in manufacturing industry. In the characteristic industrial clusters of manufacturing industry, the vast majority of small, medium and micro manufacturing enterprises cannot achieve financing through the capital market, the financing channels are still dominated by bank lending, which makes the financing difficulties of small and medium enterprises have not been solved. Taking Tianjin as an example, in 2016, the new loan for small, medium and micro-sized enterprises in Tianjin reached 219.7 billion Yuan, increased by $29.6 \%$ year on year, and the average loan interest rate was $5.5 \%$, but the main financing of small and medium-sized manufacturing enterprises in Tianjin was still bank loan, accounting for nearly $70 \%$, while the non-bank loan financing accounted for a very small proportion, so that the financing problem of small and medium-sized enterprises was not fundamentally solved. In addition, the practice that China's tax policy encourages investment to provide loans for manufacturing enterprises lacks legal and regulatory basis. Therefore, the stable source of funds for the development of manufacturing industry also depends on the establishment of venture capital system.

\section{E. Fiscal and Tax Policy of Manufacturing Industry with Regional Characteristics Lacks Suitability}

The current fiscal and tax policy of the manufacturing industry in various regions basically direct adherence to the policy issued by the state, whose policy formulation and implementation are not in combination with the local reality, and is very rarely based on the manufacturing area characteristic and the development prospect to design the encouragement policy which adjusts measures to local conditions. For example, the basic feature of equipment manufacturing is scale economy, its industrial concentration directly determines its market share in the industry, thus determines whether the enterprise has core competitiveness and whether it can't be eliminated from the market. There are few policies to cluster enterprises, encourage small and medium-sized enterprises to merge and restructure in Tianjin's fiscal and tax policy that stimulate the transformation and upgrading of the manufacturing industry, and the existing policies cannot really promote the transformation and upgrading of manufacturing industry efficiently and quickly.

\section{Perfect Suggestions on Fiscal and TaX Policy TO PROMOTE THE TRANSFORMATION AND UPGRADING OF MANUFACTURING INDUSTRY}

\section{A. Increasing Targeted Fiscal and Tax Support, and Accelerating the Restructuring of the Manufacturing Sector}

The "13th Five-year Plan" period is a critical period for the transformation and upgrading of China's manufacturing industry and the adjustment of the country's economic structure; it also provides a good environment and many opportunities for the development of the manufacturing industry. Fiscal and tax policy is adapted to a country's economic development stage, when its industrial structure changes, fiscal and tax policy should also be adjusted timely and accordingly [7]. The design of fiscal and tax policy should follow the development stage of manufacturing enterprises, and formulate and implement corresponding fiscal and tax policy in terms of capital, technology, achievement, talents and product, and encourage the transformation and upgrading of manufacturing enterprises.

The first is to encourage cross-industry and crossregional restructuring between advanced manufacturing and non-manufacturing industries, encourage enterprises to cooperate with research institutes, give full play to the scientific research strength, and reduce or exempt as much as possible the turnover tax, stamp duty and corporate income tax, etc. in the process of joint and restructuring, to let Tianjin's manufacturing industry exert the agglomeration effect, strengthen the independent research and development ability, and form the group effect. In order to promote the manufacturing industry cluster, it is suggested to construct the support fund for the multi-level infrastructure construction of manufacturing parks and for the industrial adjustment of the parks. 
Second, the main force to lead the upgrading of manufacturing industry should be put on the development and introduction of high-tech industries with high technology content. Financial support still should be given to the manufacturing enterprises that belong to the traditional industry but have high technical content in product manufacturing and are high-tech products in the industry, so as to promote their industrial transformation and upgrading. And give priority to supporting backbone enterprises with the advanced equipment manufacturing industry, accelerate mergers and acquisitions of various equipment manufacturing enterprises, integrate industrial chains and social resources, and form a number of technology-oriented new advanced manufacturing industrial clusters, so as to give full play to the synergy of strong alliances and the complementary advantages among enterprises.

The third is to give full play to the allocation function of fiscal resources and identify key areas of financial support for the development of manufacturing, give full play to the incentive role of fiscal policy, and give priority to financial support and sufficient financial support to high-tech industries and key manufacturing enterprises in the manufacturing industry, so as to promote their scale and efficiency. It is also needed to give full play to the guiding role of fiscal funds in consumption and investment, clarify the direction of financial support, support the development of key manufacturing industry, to form local technological breakthrough and promote the upgrading of the manufacturing structure.

\section{B. Implementing Innovation-driven Fiscal and Tax Policy, and Promoting Technological Innovation in Manufacturing Industry}

On the one hand, increase the financial subsidy intensity for the technological research and development of the enterprise. A multi-level enterprise research and development grant fund supported by the central and local governments shall be established to carry out support for post-event compensation; implement regulation for innovative mechanism \& scientific allocation, adhere to the principle of fairness and impartiality, follow the principles of performance management and information disclosure etc., to ensure the effect of financial support. In particular, increase financial subsidies intensity for high-end petrochemical equipment, heavy duty and high-end tools, bearings and other functional parts produced by the equipment manufacturing industry, accelerate the realization of "selfproduction" of components, and promote the transformation and upgrading of advanced manufacturing and equipment manufacturing.

On the other hand, tax reduction and exemption policy is adopted to encourage enterprises to increase investment in scientific \& technological research and development, such as increasing the deduction of $\mathrm{R} \& \mathrm{D}$ expenses, accelerating depreciation, drawing specific reserves and expanding tax credits, etc. In terms of accelerated depreciation, the standard of accelerated depreciation can be appropriately reduced, the scope of application can be expanded, and accelerated depreciation can be applied to industries with rapid equipment upgrading such as venture capital investment and financial leasing, etc.[8]; in the aspect of drawing specific reserve funds, in order to promote the transformation of scientific \& technological achievements, establish tax preferential policy for venture capital, doubly withdrawal the investment risk reserves, reduce the income tax rate, etc., which can encourage social capital to set up venture capital companies.

\section{Advocating the Introduction of Carbon Reduction Policy, and Guiding the Sustainable Development of Green Manufacturing}

With the establishment of the national carbon emission trading market and the vigorous development of the national ecological economy, it is necessary to make full efforts in green manufacturing, to introduce some fiscal and tax incentive policies for developing a low-carbon economy by eliminating outdated production capacity in heavily polluting industries, improving energy efficiency and technological innovation in enterprises, enhancing the comprehensive utilization of resources, and promoting energy conservation and environmental protection, etc., so that explore a suitable for own green manufacturing, clean production road. Firstly, enhance the environmental protection function of resource tax, formulate necessary tax preferential policies to encourage resource recycling and utilization, to improve the utilization rate of resources; in terms of value-added tax and income tax, in order to promote enterprises to vigorously develop and promote the use of production technologies and crafts that can save energy and reduce emissions, which can encourage enterprises to purchase equipment with a high comprehensive utilization rate of resources, and give them income tax preferences, or allow accelerated depreciation, etc.[9] Secondly, it should strengthen the supervision on energy conservation and reducing consumption, establish and implement scientific energy conservation and reducing consumption monitoring and evaluation index system; government can also learn from international experience, to encourage enterprises to save energy and reduce emissions by means of fiscal subsidies, incentives, transfer payments and fiscal interest discounts, so as to greatly mobilize the positive of energy conservation and reducing consumption and better guide the green transformation of manufacturing industry.

\section{Enriching the Ways of Financial Subsidy, and \\ Expanding the Channels of Funding for the Manufacturing Industry}

According to the actual situation of the enterprise, it is reasonable to use the government and to use the Public Private Partnership (PPP) model to make the social capital play a guiding role and make the capital is available for the major project construction of the enterprise. Focusing on the needs of Tianjin's economic and social development, the focus will be on intelligent manufacturing, high-end equipment and other fields, so that improve the industrial chain of manufacturing industry and realize the historical leap of manufacturing industry from great strength. For example, the establishment of advanced manufacturing R\&D 
risk fund; by using PPP mode to make social capital play a guiding role, which can accelerate the construction and technical transformation of major enterprise projects, and realize the diversification of investment subjects; increase the proportion of government credit guarantees for major advanced manufacturing and small, medium and micro manufacturing enterprises; improve preferential tax policy of venture financing for supporting advanced manufacturing, and establish a multi-channel and diversified investment and financing mechanism to support the development of equipment manufacturing through the guidance of tax policy.

\section{E. Giving Full Play to the Regional Advantages of the Manufacturing Industry and Creating a Transformation and Upgrading Environment Which Suits to Local Conditions}

In order to promote the transformation and upgrading of the manufacturing industry, it is necessary to create a fair industry tax environment, coordinate the tax burden of enterprises in different manufacturing industries, different scales and different stages of development, and solve the problem of relative fairness and balance. In order to give full play to the role of fiscal and tax policy in promoting the transformation and upgrading of the manufacturing industry, it is necessary to combine that advantage of regional and local area to create an adaptive local conditions and comprehensive policy environment for manufacturing transformation and upgrading. For example, Tianjin is a manufacturing development center in the north, an economic center in the north, a shipping hub in Haikou and a comprehensive industrial city. Tianjin's free trade area provides opportunities for Tianjin to develop internationally and improve its competitiveness. The multilateral trading system and regional trade arrangements have provided an important guarantee for driving Tianjin's economic globalization to develop forward, in order to maintain the multilateral trading system and promote the expansion of the scope of information technology agreements, government procurement policy should be improved and implemented to support innovation, promote the manufacturing $\mathrm{R} \& \mathrm{D}$ and large-scale application of innovative products. To establish Tianjin's advanced manufacturing research and development base, we must attach importance to advanced manufacturing, coordinate multilateral free trade area negotiations, increase the market share of free trade partners, and better for the development of Tianjin's manufacturing enterprises to inject new power, expand new space.

\section{CONCLUSION}

In the context of "Supply-side Structural Reform", promoting the transformation and upgrading of manufacturing industry is the key measure of national economic growth, and the only way to promote industry development and promote industry competition. By analyzing the macro situation of Tianjin manufacturing industry and combining with the challenges it faces, this paper discusses the fiscal and tax optimization path of Tianjin manufacturing industry transformation and upgrading. The rational use of fiscal and tax policy can further improve the adjustment of manufacturing structure and financing, promote the innovation and sustainable development of the manufacturing industry, and achieve the transformation and upgrading of the manufacturing industry to a certain extent, providing valuable reference for the future industrial transformation and upgrading.

\section{REFERENCES}

[1] Huang Lei, Liang Jing, Xiong Ruochen. Industrial policy implementation of supply-side reform - Empirical study on upgrading policy of manufacturing industry in jiangxi province [J] Science \& Technology Progress and Policy, 2016, 33(17): 62-66.

[2] Liu Mingda, Gu Qiang. Innovation and development of advanced manufacturing industry from the perspective of supply-side reform-A comparison of the world's major economies and its enlightenmen to our country $[\mathrm{J}]$. Comparative Economic \& Social Systems, 2016(1):19-29.

[3] Tianjin municipal bureau of statistics, Tianjin Investigation Team of National Statistical Bureau. 2016 tianji municipal national economic and social development statistical bulletin[DB/OL]. http://www.tj.gov.cn /tj/tjgb/201703/t20170314_3588851.html, 20173-3.

[4] Romer P M. Increasing Returns and Long-Run Growth[J]. Journal of Political Economy, 1986, 94(5):1002-1037.

[5] Chen Liyun, Liu Jinlan, Wang Xianya. Analysis of carbon emission right pricing and cost saving effect in tianjin municipal[J]. Modernization of Management, 2014(2):15-17.

[6] Li Shaoping, Hao Jianfang, Wang Qian. Empirical study on the effects of tax policies on energy conservation and emission reduction in energy-consuming enterprises [J]. Journal of Industrial Technology Economics, 2014(6):17-25.

[7] Zhang Lili, Li Honglei. The action mechanism of tax policy on industrial upgrading - Take the high technology industry as an example [J]. Modern Management Science, 2017(3): 84-86.

[8] Liu Ying. Research on industrial transformation and upgrading and tax system optimization [M]. Economic Sciences Press, 2015.

[9] Wu Hong. Analysis on the effects of tax policies on energy conservation and emission reduction in China [J]. Taxation Research, 2016(50:58-61. 